\title{
Poder y dominio en las relaciones culturales entre Europa y América Latina
}

Aureliano Ortega Esquivel Universidad de Guanajuato

\author{
Por el camino de la mar, \\ el pergamino de la ley, \\ la vara para mal medir, \\ y el látigo de castigar, \\ $y$ la sifilis del virrey, \\ y la muerte, para dormir \\ sin despertar. \\ Por el camino de la mar.
}

Resumen

Nicolás Guillén

El presente trabajo pretende llamar la atención sobre algunas consideraciones de orden teórico e histórico-filosófico que debemos tener en cuenta cuando emprendemos la tarea de explicar y comprender las formas que históricamente han adoptado las relaciones culturales entre Europa y América Latina. Con ese fin, se considera pertinente incluir y articular crítica y reflexivamente en nuestras investigaciones históricas e histórico-filosóficas tres consideraciones imprescindibles: $a$ ) el hecho de que nuestras naciones son resultado de un largo proceso de conquista y colonización europea; b) que dicho proceso fue programado y ejecutado bajo las determinantes económicas, jurídicas y políticas del modo de producción capitalista y de su máxima expresión cultural: la Modernidad; y c) que a pesar de ello han existido, desde siempre, discursos opositores o de emancipación que tensan críticamente aquellas relaciones culturales que nos permiten pensar una contrapropuesta cultural a la impuesta por un mundo occidental y, más allá, en la necesidad y la posibilidad de construir un proyecto civilizatorio propio. 
Palabras clave: Europa, América Latina, dominio, cultura, emancipación.

\section{Abstract}

This paper aims to draw attention about some theoretical and historical-philosophical considerations to keep in mind when we undertake to explain the ways that historically have been the relations between Europe and Latin America in cultural terms. Therefore, proposed a critical and reflective view on our historical research held on the following considerations: a) the fact that our nations are the result of a long process of conquest and colonization; b) that process was scheduled and executed on terms of capitalist production and under the idea of cultural "modernity"; c) that always have existed many "discourses of emancipation" opposing those conditions, that allow us to think the possibility of a distinctive culture and the possibility of building a project of civilization itself.

Keywords: Europe, Latin America, domination, culture, emancipation.

Tas relaciones culturales entre Europa y América Latina -como Lcaso particular de sus relaciones generales- están atravesadas históricamente por el origen colonial de nuestras naciones y por la visión colonialista o colonizada que hasta hoy predomina entre un gran número de autores e intelectuales europeos y latinoamericanos que desde las ciencias sociales o las humanidades se hacen cargo de aquéllas, de modo que aún la reflexión que parte de este lado del Atlántico conserva como signo distintivo lo que actualmente llamamos "poéticas colonizadas" (véase Subirats, 2009). Lo anterior puede observarse incluso en el conjunto de palabras que 
se utilizan para describir los estados históricos de ciertas cosas que se dicen de América Latina, empezando por sus propias denominaciones. Por ejemplo, la misma voz "América Latina”, en la que se exalta la "latinidad", fenómeno cultural netamente occidental y europeo, como divisa que la distingue de la América "anglo-sajona"; o en la palabra "Iberoamérica", para enfatizar que esta América se reinventa o simplemente "existe" -en completa ignorancia de lo que aquí sucedía antes de 1492- a partir de la irrupción de europeos en el "Nuevo Mundo" (véase O’Gorman, 1951 y 1984).

La visión colonizada se desprende igualmente de vocablos emblemáticos (y programáticos) como "descubrimiento", "conquista" y "colonización", que caracterizan el primer tramo de nuestra "verdadera" historia; o bien, en las estrategias de acoso, chantaje o tutela que ejercen sobre nuestros pueblos algunas naciones del viejo continente durante todo nuestro proceso formativo como naciones independientes a lo largo de los siglos XIX y XX (véase Galeano, 2004). Por último, encontramos ese mismo perfil programático y colonizador en el uso de palabras como "encuentro", "reconocimiento" o "globalización", que encuadran el arribo de nuestros países a la Modernidad en el marco de relaciones culturales mundializadas, en las que el tiempo y el ritmo de las instituciones están fatalmente marcados por el Occidente "desarrollado".

Construido a partir de dichas palabras-emblema, el discurso sobre la cultura y la identidad latinoamericana muestra signos de persistente colonización en la que no existe un trato de equidad, de respeto mutuo o de clara y definitiva independencia. Es evidente que dicha condición colonizada se asocia al modo en el que se impusieron y se desarrollaron, en el seno de nuestras naciones, el modo de producción capitalista y el conjunto de sus instituciones fundamentales: el Estado moderno y sus aparatos ideológicos de Estado -que en pleno uso y por efecto de su poderío "todo habla a favor de su dominio" (Marx, 1959)-. Como efecto del poder que 
ejercen el capital, sus instituciones y sus formas de vida sobre el mundo de la vida, todo discurso que se construya dentro de sus ámbitos de racionalidad o pertinencia sociocultural estará atravesado por sus "ideas" y "valores", en donde la posible crítica será disuadida, bloqueada o directamente descalificada por un discurso dominante acorde con aquellas ideas y valores. ${ }^{1}$ Frente a ello, desde siempre en América Latina han existido y se han escuchado voces críticas, voces discordantes.

Podemos pensar incluso que con los ya soterrados, disimulados y entretejidos discursos habituales y edificantes, se ha ido construyendo con los años una contrapropuesta cultural, y, más allá, se han fijado las bases ideológicas e histórico-filosóficas para construir un proyecto civilizatorio propio. Es por ello que el pensamiento crítico latinoamericano apela persistentemente a un mundo de la vida y a una identidad cultural propia, y los empata con un "relato de emancipación”, con la idea de que debemos emprender, una y otra vez, nuestra propia lucha por la libertad y por nuestra verdadera independencia. $^{2}$

${ }^{1}$ En La americanización de la modernidad (Echeverría, comp., 2008) se pueden consultar los trabajos de Bolívar Echeverría, "La modernidad 'americana' (claves para su comprensión)"; de Rolando Cordera, "México y su economía política de la modernización (hipótesis para un relato)”, y de Raquel Serur, "La barbarie del Imperio y la 'barbarie' de los bárbaros". Es ya un clásico a este respeto el trabajo de Leopoldo Zea "El Occidente y la conciencia de México” (1953).

${ }^{2}$ Sobre el tema de la "liberación" latinoamericana se han escrito decenas de trabajos de mérito desde el inicio mismo de nuestra vida como naciones independientes, que siguen vigentes. Para no recargar estas notas con nombres conocidos de sobra, solamente consignamos algunos autores que en distintos momentos de nuestra historia se han hecho cargo del tema: Simón Bolívar, "Carta de Jamaica o Contestación de un americano meridional a un caballero de esta isla" (Bolívar, 1982); José Martí, "Nuestra América” (publicada hacia fines del siglo XIX y reproducida en Hidalgo et al., 1962); Fidel Castro, "Primera declaración de La Habana” y "Segunda declaración de La Habana" (Castro, 1972); Enrique Dussel, Introducción a una filosofía de la liberación latinoamericana (1977) y Sader, El nuevo topo. Los caminos de la izquierda latinoamericana (2009). Es preciso agregar a estos autores los múltiples ejemplos de resistencia indígena, desde Huamán Poma de 
En las líneas que siguen proponemos algunas consideraciones de orden teórico e histórico-filosófico que, a nuestro juicio, debemos tener en cuenta cuando tratamos de explicar y comprender las formas que históricamente han adoptado las relaciones culturales entre Europa y América Latina. Con ese fin, consideramos pertinente incluir y articular crítica y reflexivamente en nuestras investigaciones tres emplazamientos problemáticos fundamentales: a) el hecho de que nuestras naciones, tal y como actualmente se configuran, son el incontestable resultado de un largo proceso de conquista y colonización europea que continúa vigente a través de diversos procesos y mecanismos de dominación económica y cultural; b) que dicho proceso fue y es actualmente programado y ejecutado bajo las determinantes económicas, jurídicas y políticas del modo de producción capitalista y del complejo culturalinstitucional que se concibe y retrata con el nombre de Modernidad; y c) que a pesar de que la fuerza y la eficacia avasallante de aquellas determinantes históricas han estado presentes, a la par han existido discursos opositores o de emancipación que tensan críticamente los modos en los que han cobrado cuerpo las relaciones entre Europa y América Latina, lo cual nos permite reconocer y recuperar diversas experiencias de resistencia y lucha en contra de la cultura impuesta por un mundo occidental, y, más allá, nos obliga a pensar en la necesidad y la posibilidad de construir un proyecto civilizatorio propio.

\footnotetext{
Ayala y el Inca Garcilaso de la Vega, hasta los movimientos que en México (zapatistas, huicholes, purépechas), Bolivia, Ecuador y Perú se identifican con un nuevo programa de liberación. Véase: Tawantinsuyu (Cinco siglos de guerra qheswaymara contra España) (Wancar, 1980); La potencia plebeya. Acción colectiva e identidades indigenas, obreras y populares en Bolivia (García Linera, 2008) y Dispersar el poder. Los movimientos como poderes antiestatales (Zibechi, 2007).
} 
Cualquier acercamiento al examen crítico de la naturaleza, el carácter y las formas que a lo largo de cinco siglos han adoptado las relaciones culturales entre Europa y América Latina deberá considerar por lo menos tres principios de orden teórico que inciden de manera determinante en el alcance y la profundidad de nuestro análisis, en el entendido de que al margen, o en ausencia, de dichos presupuestos, nuestras estrategias de acercamiento e interpretación a la multiplicidad de temas y problemas que abarcan las expresiones "cultura" y "cultura latinoamericana" carecerán de una base o de una plataforma lo suficientemente sólida, y correrán el riesgo de aparecer ante el juicio crítico de sus destinatarios como resultado de cierta arbitrariedad interpretativa, cargada hacia los vicios que siempre han entrampado el conjunto de intervenciones sobre "nuestra América" en las vías idealistas del historicismo, el psicologismo, el fenomenalismo de orientación ontológico-existencial y más recientemente la hermenéutica culturalista. Estas posiciones de discurso se han resuelto como una forma de "impresionismo" interpretativo cuyo límite fundamental es que inevitablemente deja las cosas como están; es decir, contribuyen muy poco, o de manera muy ambigua y episódica, a la solución de los agudos problemas de autoconciencia y autognosis que endémicamente han sufrido y todavía sufren nuestros pueblos.

Cabe agregar, antes de entrar de lleno en la exposición detallada de aquellos principios teóricos, que éstos son contemporáneamente de naturaleza histórico-filosófica, y, si insistimos, igualmente de naturaleza histórico-concreta, de manera que podemos encontrar aquí y allá suficiente evidencia factual de ellos a través del examen riguroso y atento, de eventos, procesos y estados de cosas reales cuyo testimonio, para nuestra fortuna, está recogido en innumerables expedientes y registros de todo tipo; o bien, grabado en la 
carne viva, en ese vasto sistema de experiencias que conforman el mundo de la vida de nuestro continente y que se expresa en las más diversas formas del folclor, el arte, las tradiciones literarias y los sistemas de signos con los que articulamos nuestras creencias y tratamos de establecer un diálogo con nuestros mayores. Esto, para dejar en claro que nuestro esfuerzo de autognosis se deslinda y toma distancia de aquellas consideraciones filosóficas e históricofilosóficas que en el pasado, e incluso en el presente, han buscado entidades esenciales y abstractas como el "ser", la "esencia”, la "vocación" y el "destino" de Latinoamérica, para anclar en ellas no propiamente un programa de investigación crítico-reflexivo, sino un agregado de buenas intenciones de orden metafísico (véase Bartra, 2006), que, en el mejor de los casos -como pueden ejemplificarlo las celebridades internacionales de Octavio Paz, Luis Villoro o Leopoldo Zea-, habilitaron a sus autores como excelentes ensayistas, valiosos maestros universitarios o cuestionables líderes de opinión, pero cuya obra se inscribe de manera desigual, y ambigua, en nuestro accidentado proceso de autognosis.

La primera determinante de orden teórico de la que debemos hacernos cargo para abordar posteriormente el problema de las relaciones culturales entre Europa y Latinoamérica es -o tiene que ver- el hecho de que el llamado "descubrimiento" de América, fechado el 12 de octubre de 1492, constituye una pieza maestra, un engranaje propiamente esencial en el proceso de consolidación y dominio hegemónico mundial del llamado modo de producción capitalista, y, contemporáneamente, representa la señal de arranque de ese proceso sociocultural concomitante o consustancial al desarrollo capitalista que solemos llamar Modernidad. Si no entendemos esto, corremos el riesgo de no entender nada de lo que 
sucede con nuestro desarrollo o subdesarrollo cultural, ni más ni menos porque a partir del "descubrimiento", el proceso de conquista y colonización que se desencadena, y que se despliega a lo largo de tres siglos, obedece a la lógica del capital, particularmente a la fase del desarrollo que se conoce como "acumulación originaria”. Ésta tiene como condición la existencia y la circulación de una masa enorme de metales preciosos (oro y plata) que bajo la forma de "bienes de capital" hacen posible el financiamiento necesario para construir infraestructura portuaria o carretera y el desarrollo de talleres manufactureros e industriales que multipliquen y diversifiquen los procesos de acumulación de riqueza, amplíen los medios de circulación mercantil y dineraria, patrocinen el progreso de la ciencia y la técnica, sufraguen la "invención” de máquinas e instrumentos de producción y contribuyan a la consolidación de la "economía-mundo" europea (véase Davis, 1976). Está claro, aunque no podamos explicarlo aquí como se debe, que sin "descubrimiento" no existirían la plata y el oro americanos, ni el mercado mundial, y que sin ellos no existe todo lo demás.

Debemos agregar que el "descubrimiento" es también el punto de arranque de la Modernidad en cuanto a sus premisas y sus resultados, pues suponen el derrumbe definitivo de la concepción medieval y teológica del mundo; constituyen la prueba fáctica de que la razón, el cálculo, la medición, el interés, el ingenio y la fortuna son las características del nuevo hombre europeo, del hombre moderno. Igualmente, estas características prueban que la filosofía, la sabiduría y la ciencia de los "hombres prácticos", los experimentadores y los ensayadores, son infinitamente superiores al canon teológicoescolástico, y que el conocimiento puntual de la naturaleza y de la historia produce mejores lecciones para la vida que toda la retórica y la dialéctica ancestrales. Esto nos pone en la vía de entender a la Europa que "descubre" América -así se desagregue ella misma en naciones distintas y antagónicas como una entidad político-nacional 
en expansión- como un conjunto abigarrado de naciones -que en el caso de Espańa, Inglaterra, Holanda o Francia apenas se ensayan como Estado-nación propiamente modernos- en plena ebullición y transformación interna, sujetas a un ímpetu "descubridor-conquistador", ya sea en el ámbito de lo geográfico-cosmológico, lo científico-filosófico y lo cultural, condiciones que se experimentan como recursos irrenunciables para su propia subsistencia.

La segunda consideración que habremos de tener en cuenta en el examen de nuestra problemática es el hecho de que América haya sido "descubierta", conquistada y colonizada precisamente por esa Europa en expansión. En primer término debemos de hacernos cargo del análisis semántico y pragmático de las palabras con las que se describen estos eventos, cuya condición casi canónica al interior del discurso y el lenguaje de la historiografía universal hacen sumamente difícil percibir sus connotaciones culturales. Se trata de palabras cargadas de sentido histórico; no son palabras que describan hechos, sino el significado de esos hechos. ${ }^{3}$ Pensemos en la palabra "descubrimiento". Se descubre lo oculto, lo ignoto, lo que a la mirada del agente activo de un hecho no existía o era desconocido. Hacia 1492, para la tradición histórica y cosmológica inspirada en la sabiduría judeo-cristiana únicamente existían tres mundos: Europa, Asia y África. El Orbis Terrarum no era distinto al que habían evocado los textos de Isaías o los saberes naturalistas de un Plinio o un Estrabón. Para la mirada europea América no existía; pero advino a la existencia por medio de un "descubrimiento" por el hecho de ser descubierta. Esto le da al des-

\footnotetext{
${ }^{3}$ Respecto a este punto, ya se han mencionado los trabajos fundamentales de Edmundo O'Gorman.
} 
cubridor todo el crédito, mientras introducimos en lo descubierto la condición de cosa, de objeto del "descubrir", y, posteriormente, objeto del "conocer", del "poseer", del "dominar", del "explotar". El hecho histórico se convierte provisionalmente en un evento de índole epistemológica que no tiene nada de inocente, de una relación sujeto-objeto en donde el lado activo recae en el sujeto-agente: el europeo Colón; y el lado pasivo, de cosa, en el objeto América, clausurando de entrada o haciendo muy difícil el posterior reconocimiento de una subjetividad y de una conciencia específicamente americanas. Pero por ese camino, el sujeto-agente y todos aquellos a quienes representa adquieren derechos sobre lo descubierto; al fin y al cabo América es una cosa que de acuerdo con la idea europea de "propiedad" y de "conocimiento" pertenece al rey y al papa. El papa Alejandro VI, sin duda un dechado de virtudes cristianas, es quien divide el mundo "descubierto" en dos porciones: a España le confiere la parte occidental y a Portugal el resto. Se sabe que, unos cuantos años más tarde, cuando se "descubren" las civilizaciones mesoamericana y andina, herederas de una cultura sorprendentemente rica y diversificada, el mal ya estaba hecho. Por pertenecer a la cosa descubierta son ellas mismas cosas. Su conquista y su posterior reducción a esclavitud y vasallaje son asumidas y conceptualizadas por el conquistador como procesos "naturales". Apelando a la autoridad de Aristóteles (véase Ginés de Sepúlveda, 1996) y a la doctrina de la "servidumbre natural", la intelectualidad europea que en Valladolid o Salamanca discute sobre la "humanidad", la condición civil y los derechos de esa vasta porción de hombres, justifica racionalmente su reducción a servidumbre, el que hayan sido vasallos de los monarcas europeos (véase: De Vitoria, 2000; Brufau Prats, 1988) y el que su mundo de la vida, sostén de su expresión y su cultura, fuera sistemáticamente destruido.

Es importante destacar el nexo entre nuestra primera consideración histórico-crítica y los hechos anteriores porque el capitalismo 
es un sistema económico que para su acumulación y reproducción ampliada mantiene como premisas dos procesos básicos y concomitantes. En primer lugar está la recuperación del proceso de su producción, circulación y consumo de los valores invertidos en él, lo que se da a condición de extraer del trabajo humano todo el valor que éste sea capaz de agregar al producto (lo cual convierte a los trabajadores al servicio del capitalista en una rica fuente de valor agregado o plusvalor) mientras exige del mercado el "mejor precio de venta" para sus mercancías, que son los objetos que por su condición de "bienes producidos" representan el conjunto de valores agregados en el proceso de "realización" del capital. En segundo lugar, y dado que la explotación del trabajo tiene límites humanos, sociales y jurídicos expresos, el capital busca reproducirse a través de la expansión continua de sus esferas de realización, incorporando nuevos trabajadores a nuevas factorías y abriendo indiscriminadamente nuevos y más grandes mercados, hasta abarcar el mundo entero y constituir una economía-mundo; es claro que el capital no puede dejar de hacer una y otra cosa, a reserva de caer en una "crisis de realización". De manera que si Europa "descubre" América no es únicamente en virtud del ímpetu moral de algún puñado de aventureros y sońadores, sino como respuesta a la lógica expansiva e implacable del capital. ${ }^{4}$

Sin embargo, si bien el capitalismo exporta su lógica a los lugares que conquista, no necesariamente lleva sus instituciones jurídico-políticas más avanzadas, su ciencia, su técnica, su filosofía y su cultura, en suma, su modernidad. Por el contrario, trae a los lugares conquistados lo estrictamente necesario para expoliarlos, para extraer de ellos todo el oro, la plata y los bienes que necesita su reproducción ampliada (minas, factorías, plantaciones, puertos,

\footnotetext{
${ }^{4}$ Sobre la lógica de la expansión capitalista, sigue siendo un clásico el estudio que se resume en los capítulos XXIII y XIV del tomo primero de El capital, de Marx, obra citada.
} 
vías de comunicación, iglesias, presidios y cuarteles). Y si entre esas necesidades está la de crear una burocracia dirigente y administrativa, será acaso igualmente necesaria la creación de instituciones de enseñanza, de lugares de esparcimiento y una creciente oferta de espectáculos, pero nada más - este "nada más" debe entenderse literalmente-. Las metrópolis sólo trasplantaron a sus colonias aquellos aspectos de la vida social y cultural que garantizaban la buena marcha de sus negocios. Del mismo modo, los pueblos conquistados jamás recibieron de sus conquistadores algo más que instrumentos culturales mínimos: la lengua y la religión. Sobre todo la religión, para desarrollar una mínima conciencia o un saber de sí que se agotaba justamente en el hecho de saberse colonizados. ${ }^{5}$

Tan voraz y destructiva es la maquinaria colonizadora, que la suerte que corren los indígenas americanos en los planos social y cultural la comparten en muchos aspectos los propios colonizadores, quienes a la vuelta de una generación ya son conocidos despectivamente como "indianos". Para estos sujetos marginales las mercedes y prebendas reales, las concesiones mineras, los repartimientos de tierras y vasallos, los puestos públicos, los mandatos más distinguidos y las más altas dignidades civiles o eclesiásticas estaban vedados por completo. Tenemos aquí el origen de una asimetría consustancial en la relación Europa-América. Una desigualdad que se origina en el espacio de la producción y la distribución de la riqueza que se hace extensiva y refuerza lo que podemos reconocer como asimetría sociocultural; es decir, la condición de subdesarrollo, minoría de edad o franca desventaja que presentan

\footnotetext{
${ }^{5}$ La ciudad letrada, trabajo poco frecuentado de Ángel Rama, es, sin embargo, una obra fundamental para comprender cómo los "intelectuales", los "letrados" latinoamericanos, han sido a lo largo de los siglos una pieza fundamental en el proceso de colonización cultural europea, aunque, contemporáneamente, esa "letra" que llega junto con la ley y la religión, también esconde un primitivo acervo crítico y un balbuceante aliento de liberación.
} 
tanto los hombres como las instituciones sociales y culturales americanas frente a sus pares europeos. Aquí todo es pequeño, todo es lábil, todo es resultado de la medianía -o la pereza-, aquí todo es fruto de una imitación exógena, aquí todo carece de originalidad.

El tercer aspecto que debemos destacar no ha sido valorado suficientemente sino hasta tiempos muy recientes a la hora de abordar y analizar crítica y reflexivamente las relaciones culturales entre Europa y Latinoamérica. Nos referimos concretamente al largo expediente de la resistencia que los pueblos originarios de América, y después los americanos propiamente dichos, han podido oponer a la irrupción de extraños en su tierra y a la destrucción sistemática de sus formas de vida, sus lenguas, sus tradiciones y sus soportes culturales, como los episodios de resistencia y lucha que desde el momento mismo de la llegada de los europeos a estas tierras han emprendido hombres y mujeres concretos en defensa y conservación de lo que creen más propio. Para lo cual han tenido que echar mano de su historia, de sus tradiciones y de sus recursos comprensivos y expresivos; o bien, cuando ello ha sido posible, de aquellos fragmentos de la cultura europea que, adaptados a nuestra circunstancia y nuestras necesidades, proveen las bases teóricas o intelectuales que en distintos momentos han requerido la construcción de un discurso y una práctica opositores frente al dominio irrestricto de lo extraño. Los ejemplos abundan, aun cuando nuestros intelectuales "atentos al pulso de su sangre europea" no los hayan querido o sabido reconocer.

El punto es importante porque corrige tendenciosamente el vicio historicista de presentar la escena latinoamericana exclusivamente como una relación dramática de victimario y víctima, de amo y esclavo, de señorío y servidumbre. A pesar de que existen muchas razones y ejemplos para pensar las cosas de esa forma, 
existen también, y se acumulan con los años y los conocimientos, múltiples ejemplos de resistencia cultural activa, de desplazamientos simbólicos y conceptuales, de influencia directa de lo americano en la conformación de algo que por efecto de la historia ya no es estrictamente indígena, pero tampoco es europeo. El mestizaje cultural es una realidad americana que no oculta la voluntad de destrucción sistemática y tenaz de los soportes básicos de la cultura indígena y de su contundente éxito a cuenta de los conquistadores. Pero, tanto la resistencia que en busca de fundamentos echa mano de lo americano, como la resistencia que acude a los recursos teóricos, filosóficos y doctrinales que el humanismo crítico y el discurso igualitario y de emancipación que la Modernidad le proporcionan, configuran un instrumental teórico y simbólico que permiten estar a salvo de las formas más degradantes de conquista material y espiritual, pilares del mundo de la vida y la cultura propias. Con ellos, en unos cuantos años, Latinoamérica será capaz de construirse una conciencia histórica y de disputar a Occidente la hegemonía sociocultural de sus propios pueblos. Pero esta resistencia y lucha no generan únicamente anulaciones recíprocas, $y$ tampoco conforman un "crisol" en el que se encuentran y funden dos culturas, como solía decirse para lavar la mala conciencia de los conquistadores. La destrucción de la cultura indígena es real, de manera que de la lucha por la supervivencia no se obtiene una venturosa síntesis, sino una oposición violenta, una verdadera explosión del sentido; lo nuevo no es necesariamente una amalgama, sino una suerte de bricolaje que toma de aquí y de allá los restos útiles dejados por la destrucción para reconstruir con ellos una nueva e inédita propuesta cultural. ${ }^{6}$

\footnotetext{
${ }^{6}$ Como ya se dijo (nota 2), el expediente de la resistencia en todos los planos de la vida social, cultural y artística latinoamericana es, a estas alturas, lo suficientemente vasto para que la "ignorancia programada" del pensamiento colonizado y europeizante pueda soslayarlo. (Véase: García Canclini, 1990; De Sousa Santos, 2009).
} 
Es preciso insistir en el peso específico y la presencia que portan esa resistencia y autoconciencia latinoamericanas a la hora de hacer el recuento de nuestro derrotero cultural y nuestras relaciones con Europa. Esto permite explicarnos por qué en el inicio mismo de la colonización europea Bartolomé de las Casas y Alonso de la Veracruz fueron capaces de reconocer y denunciar la universalidad abstracta del Humanismo y tuvieron que desplazar el núcleo de su argumentación a favor de los indígenas americanos hacia el plano inédito, propiamente fundacional, del pensamiento antropológico y la liberalidad republicana. Asimismo, podremos interpretar fenómenos artísticos como el "realismo mágico" o los murales de Diego Rivera, la poesía de Nicolás Guillén o de João Cabral de Melo Neto, la novela de Augusto Roa Bastos y Juan Rulfo, el teatro de Augusto Boal y Luis Valdez o la arquitectura de Juan O’Gorman, Lucio Costa y Oscar Niemeyer como una mala asimilación, como mal uso o un uso radicalmente crítico, lúdico, irreverente y cínico de los lenguajes artísticos occidentales. ${ }^{7}$ Por último, estaremos en condiciones de entender los motivos y saber a qué profundas fuentes históricas y culturales responde el hecho de que en las grandes cumbres político-económicas en las que participa el presidente boliviano Evo Morales, se dé a sí mismo el gusto de epatar a sus colegas y "líderes mundiales" con la negra pero significativa humorada de jugar, mientras habla, con una hoja de coca...

\footnotetext{
${ }^{7}$ Basta buscar en Internet información actual sobre pensamiento, arte y cultura latinoamericanos para darse una idea de lo que a todo lo largo y ancho de nuestro subcontinente se hace actualmente en favor de aquella resistencia, pero, sobre todo, de la miríada de propuestas que la transforman en nuevas y pertinentes formas de lucha y de liberación.
} 


\section{Bibliografía}

Bartra, Roger, 2006, La jaula de la melancolía. Identidad y metamorfosis del mexicano, México, Random House Mondadori.

Bolívar, Simón, 1982, "Carta de Jamaica o Contestación de un americano meridional a un caballero de esta isla", en Textos. Una antología general, México, SEP/UnAM.

Brufau Prats, Jaime, 1988, La Escuela de Salamanca ante el descubrimiento del Nuevo Mundo, Salamanca, San Esteban.

Castro, Fidel, 1972, "Primera declaración de La Habana" y "Segunda declaración de La Habana”, en La Revolución Cubana 1953/1962, México, Era.

Cordera, Rolando, 2008, "México y su economía política de la modernización (hipótesis para un relato)", en La americanización de la modernidad, (Bolívar Echeverría, compilador), México, Era/unAm.

Davis, R., 1976, La Europa atlántica. Desde los descubrimientos hasta la industrialización, México, Siglo XXI.

Dussel, Enrique, 1977, Introducción a una filosofía de la liberación latinoamericana, México, Extemporáneos.

Echeverría, Bolívar, compilador, 2008, "La modernidad 'americana' (claves para su comprensión)", en La americanización de la modernidad, México, Era/unam.

Galeano, Eduardo, 2004. Las venas abiertas de América Latina, México, Siglo XXI.

García Canclini, Néstor, 1990, Culturas hibridas. Estrategias para entrar y salir de la modernidad, México, CNCA/Grijalbo.

García Linera, Álvaro, 2008, La potencia plebeya. Acción colectiva e identidades indigenas, obreras y populares en Bolivia, Buenos Aires, Clacso/ Prometeo. 
Ginés de Sepúlveda, Juan, 1996, Tratado sobre las justas causas de la guerra contra los indios, México, FCE.

Martí, José, "Nuestra América”, en Hidalgo, M. et al., 1962, Hispanoamérica en lucha por su independencia, México, Cuadernos Americanos.

Marx, Karl, 1959, El capital. Crítica de la economía política, tomo I, México, FCE.

O’Gorman, Edmundo, 1984, La invención de América, México, SEP/FCE. , 1951, La idea del descubrimiento de América, México, unam.

Rama, Ángel, 2009, La ciudad letrada, Monterrey, Fineo.

Sader, Emir, 2009, El nuevo topo. Los caminos de la izquierda latinoamericana, Barcelona, El viejo topo.

Serur, Raquel, 2008, "La barbarie del Imperio y la 'barbarie’ de los bárbaros", en La americanización de la modernidad, (comp. Bolívar Echeverría), México, Era/unAM.

Sousa Santos, Boaventura de, 2009, Una epistemología del Sur, México, Clacso/Siglo XXI.

Subirats, Eduardo, 2009, Las poéticas colonizadas de América Latina, México, Universidad de Guanajuato.

Vitoria, Francisco de, 2000, Reelecciones. Del Estado, de los indios y del derecho de la guerra, México, Porrúa.

Wallerstein, I., 1979, El moderno sistema mundial, tomo I, México, Siglo XXI.

Wancar (Ramiro Reynaga), 1980, Tawantinsuyu (Cinco siglos de guerra qheswaymara contra España), México, Nueva Imagen.

Zea, Leopoldo, 1953, "El Occidente y la conciencia de México", en Conciencia y posibilidad del mexicano, México, Porrúa.

Zibechi, Raúl, 2007, Dispersar el poder. Los movimientos como poderes antiestatales, Barcelona, Virus. 